\title{
Interactive comment on "Hydrometric
} measurements in peatland-dominated, discontinuous permafrost at Scotty Creek, Northwest Territories, Canada - Changing Cold Regions Network (CCRN) Special Observation and Analysis Period (SOAP)" by Kristine M. Haynes et al.

Anonymous Referee \#2

Received and published: 15 July 2018

Review of "Hydrometric measurements in peatland-dominated, discontinuous permafrost at Scotty Creek, Northwest Territories, Canada - Changing Cold Regions Network (CCRN) Special Observation and Analysis Period (SOAP)" by Kristine M. Haynes, Ryan F. Connon, and William L. Quinton 
Summary: This brief communication is an interesting and highly suitable contribution to Earth System Science Data (ESSD). The paper is generally well-written and figures are very clear and entirely appropriate to illustrate key aspects of the dataset. This report provides guidance that the authors should consider in revising their manuscript.

General Comments:

1) One requirement for publication in ESSD is the inclusion of clear statements on the limitations of the datasets, which are lacking in the paper. For instance, what are the operating range, accuracy and precision of the instrumentation used? Are there gaps in the datasets and was in-filling performed on these gaps (if any)? Was there any quality control/analysis performed on the data? In any case, information on the limitations of the observational data should be included in a revised paper.

2) Similarly, the journal requires the datasets to be openly accessible to warrant publication. While the datasets reported in this paper are indeed available in an online data repository at Wilfrid Laurier University, there is an embargo on the data until 31 May 2019. Is it therefore too soon to publish this article when the data are not readily accessible? This is particularly a concern if one wishes to verify the quality of the datasets, which should be deemed sufficient to warrant publication.

3) The journal requires statements on the author contributions and competing interests, as well as a special issue statement, prior to the Acknowledgements.

Specific Comments:

1) P. 1, lines 1-4: The title should better reflect the datasets described in this paper. Perhaps the title should thus be modified to "Hydrometeorological measurements ..." or "Micrometeorological measurements ..." Further to this, is the second part of the title necessary? If so, then the en dash should be replaced with "during the".

2) P. 1, line 15: Change to "1 October".

Discussion paper

3) P. 1, line 26: Replace "dramatic" with "substantial" or another similar word. 
4) p. 2, line 16: Use "terrain" in the singular form.

5) p. 2, line 32: Delete the commas after the months.

ESSDD

6) P. 4, line 7: Change to "All data were".

7) P. 4, line 18: Revise to "these data have"

8) p. 5, lines 1-5: At what depth are the 'deep groundwater temperatures' being measured? How to they compare to the depths of the soil temperatures reported in Section $3 ?$

9) P. 5, lines 11-12: How was the partitioning of the precipitation into its liquid and solid component achieved? Is this based solely on a $0^{\circ} \mathrm{C}$ threshold?

10) P. 5, line 13: Was there only one snow survey conducted or multiple ones prior to snowmelt? On what dates were these snow surveys conducted? What were the average snow depths/snow water equivalents during the snow surveys? What is the precision of these snow measurements and possible sources of errors? More information on this component of the hydrometeorological datasets is needed.

11) P. 5, line 21: Revise the text to: "were recorded at 30-minute intervals and were corrected ..."

12) P. 5, line 27: Change to "3 May".

13) P. 6, line 1: Change to "were related".

14) P. 6, line 4: Change to "are presented".

15) P. 6, line 8: In what format are the datasets archived? What metadata are available with these files?

16) P. 7, line 15: Update this reference with an article number or page range if possible.

17) P. 7, line 31: Update the status of this reference if possible. 
18) P. 9, line 1: The journal may require all authors on this reference be listed here instead of "et al."

ESSDD

19) P. 9, line 6: Add the paper number for this article.

20) P. 10, Table 1: Consider adding the operating range, precision and accuracy of each instrument to the table.

Interactive

comment

21) P. 14, Figure 3: How well do the water content reflectometers operate in frozen ground? What may be the source of the spike in ground heat flux at the bog in spring 2015 , or are these spurious measurements?

Interactive comment on Earth Syst. Sci. Data Discuss., https://doi.org/10.5194/essd-2018-68, 2018. 